\title{
Research on the Evolution of Sports Industry Structure in Developed Countries
}

\author{
Sanying Peng \\ Department of Physical Education, Changzhou Campus of Hohai University, Changzhou City, \\ 213022, China \\ pengsy1979@163.com
}

Keywords: developed country; the structure of sports industry; evolution; analysis.

\begin{abstract}
As the most developed countries in the world, the Structure of Sports Industry in the United States, Japan, Britain and other developed countries is unique in terms of market mechanisms, financial support, mindset, industrial policy support and innovation ability. Through literature review, expert interview and logic analysis, this article first analyzes the features and current situation of these developed countries, and then compares the structure with the existing problems in China's Sports Industry. Based on those advanced practices and patterns in developed countries, this article is expected to provide learning template for the development of China's industrial structure, so as to optimize and upgrade its sports industry.
\end{abstract}

\section{Introduction}

The definition of 'Sports Industry Structure' is varying among academic opinions. According to some research, it's the composition of sports industry within the production department, and the combination between them, the technical economic ties and quantity proportion relationship [1]. Some scholars claim that the concept of sports industry structure is extended from the industrial structure in the industry economics, and it refers to the internal structure of industrial economic system [1]. Some scholars put forward that Sports Industry Structure is featured with the characteristics evolution from low level to high level [2]. They also propose that the rationalization of industrial structure, the deepening of the industrial structure and the optimizing of the sports industry structure are necessary stages [3]. 'Optimizing the Sports Industrial Structure is the final direction in the evolution of industrial structure, and is also established on the basis of Sports Industry Structure which is to achieve the stage of rationality and sophistication' [4]. In a word, it can be summarized as the optimization adjustment of Sports Industry Structure, which is the outcome of integrated action by three aspects, government intervention, market regulation and corporate self-regulation. It can help us implement targeted strategy by researching these concepts, which also promote the optimization and upgrading of our country's Sports Industry Structure. Finally, it'll contribute the rapid growth of China's sports industry.

The rapid development of economy in the developed countries has been promoting the evolution of the Sports Industry Structure and leading the development of sports industry trend. Looking around the world, sports industry has become the mainstay industry of national economy in many developed countries. Therefore, it is necessary to study the evolution path of their sports industry and their development trend, which is beneficial to optimize and upgrade of our country's Sports Industrial Structure.

\section{Analysis of developed countries' sports industry structure evolution}

\subsection{Analysis of the structure evolution of sports industry in Japan}

Japan is one of the developed economies in the world, and it is also the most developed country in Asia, The development pattern of sports industry in Japan is the mode with the participation of Japanese government. In the process of developing sports industry, Japanese government plays a 
leading role. Similarly, the Chinese sports industry is also adopting the government-leading pattern. Therefore, studying the evolution of Japanese Sports Industry is far more significant, which provides successful experiences for the development of China' sports industry.

The mainstay industry of Japanese sports industry is the sporting goods industry [5]. For a long time, the scale and profits of Japanese sporting goods have long been ranked in the second place in the world, only slightly less than that of the United States. Japanese history of sporting goods industry can be traced back to early Meiji period. Such a long developing period is similar to the developed countries in European and American. Japan began to promote leisure sports all over the country at the end of the Second World War. Thus, Japan became one of a few countries that carried out leisure sports at a earlier time. In 1938, Japan established the Leisure Sports Association, which was recognized by the Ministry of Education as the nature of the Corporation Foundation. Since then, Japan held a national recreational sports meeting annually. According to the statistics, by the end of 2010, this event has been held successfully for 64th sessions, and it has become a historical and traditional leisure sports activity in Japan. In recent decades, this association has developed rapidly. Leisure sports industry is becoming increasingly important and undertaking a more significant mission when faced with some problems in the current society, such as 'the phenomenon of aging population, juvenile crime surge, as well as the deterioration of the natural environment' [6]. Japanese leisure sports meeting was held in deferent places each year, which is also the essential content of the Japanese social mass sports life. Consequently, it contributes to the global development of leisure sports industry in Japan. Like other developed countries, Japan functions as the role and status to lead the new trend of the sports industry. In addition, in recent years, along with the development of racing, tennis, golf and other events, more and more sports activities have gradually become the favorite of many young people in Japan, which finally developed into a popular sport fashion.

As Japanese sports industry is under the leading of the sporting goods industry, its development level has always been at the first-class level in the world. At the same time, the continuous development of sports industry has also stimulated the rapid development of Japanese economy. Japan is identified as the world economic power and the country that developed after Implementation of Sports Industry. China, as another Asian country, could benefit from the experience of Japanese sports industry's.

\subsection{Analysis of the structure evolution of sports industry in America}

The successful of American sports industry is actually accompanied by the blooming of professional sports industry [7]. In fact, the establishment of Major League Baseball opened the prelude and development of American professional sports industry, and also laid a foundation for the development of American sports industry. With the continuous success that major league baseball system has achieved, a variety of other popular activities have been carried out and emulated to achieve success. Thus, American professional sports industry begins to flourish, and at the same time, it brings rapid development among American fitness and leisure industry and sporting goods industry.Ultimately, it makes American sports industry develops more prosperously.

We all know that the rise of American Fitness and Leisure Sports Industries further promotes the striding-forward of American sports industry. In the early 1900s, the US economy had been boosted and developed prosperously. Under this background, fitness and recreational sports in the United States had also been conducted to get extensive cooperation and development. Since then, a popular leisure culture was formed. At that time, the Americans began to consider how to make fitness and leisure activities conducive to the development of American society. Non-profit organization emerged to build fitness and leisure sports organizations. In sports health clubs, people regularly participate in fitness and leisure activities that it is becoming increasingly popular. Various forms of physical activities have promoted the prevailing of fitness and leisure activities that the Fitness and Leisure Industry is rapidly becoming one of the fastest growing industries in the United States in the early 20 th century.

Following the success of Major League Baseball, other US sports have also entered the market and successfully developed into a professional and commercial sports industry. In 1905, the establishment 
of American's Sporting Goods Manufacturers Association (SGMA) marked the coming of the era of American sports goods industry. As the needs for sports products among Americans is demanding increasingly, sporting goods industry in American had a bright prospect and achieved unprecedented development.

After the Second World War, the US economy entered an unprecedented period of rapid development, and soon laid the status of world hegemony. Under this superior economic environment, the development and growth of sports industry was also unprecedented. Fitness and leisure sports industry, professional sports and sports goods manufacturing industry in the United States show a good momentum of rapid development, making US become the world's most developed country in sports industry and remain its position ever since.

\subsection{Analysis of the structure evolution of sports industry in British}

Britain is the birthplace of the modern sports industry. Its developed economic level and the social culture of athleticism have ranked British sports industry on the list of the world advanced level [8]. Most modern sports are originated from Britain, which is due to the passion that British people show to sports. They not only love watching sports, but also desire to participate in sports. Such a highly sports-consciousness and tendency for sports consumption naturally become a hotbed for the development of sports industry in British. The structure of sports industry in British mainly consist of fitness and leisure industry, professional sports industry, sports goods industry, sports gaming industry and sports sponsorship and advertising and so on. Similar to USA, the mainstays of British sports industrial structure still incorporate three constituents: fitness and leisure industry, professional sports industry and sports goods industry, which contribute to the development of sports industry.

Britain pioneered a form of club system to conduct business in the sports industry organization. In a historical view, the sports industry originated in Britain has its inevitable reasons, as the formation of sports industry depends on the development of economy and the establishment of market economic system. In the mid 18th century, England established a market economy system. Together with the following industrial revolution, the United Kingdom effectively promoted the rapid development of the productive forces at that time. They also broadened their domestic market and international market. Since then on, British sports market naturally developed under a market and professionalization model.

The most representative professional sports in British sports industry must belong to England Football Super League [9]. However, as a pillar industry of British sports industry, the development of the fitness leisure industry also represents the history of British sports industry. Before the industrial revolution, fitness and leisure activity in Britain was a kind of noble entertainment, belonging to a handful of wealthy social nobility, which was unaffordable to ordinary people. With the completion of industrial revolution, the British society gradually developed its social productive forces, and people's living standard had been greatly improved. At the same time, along with industrial production, the British are liberated from daily manual work, thus they have plenty of free time to participate in sports fitness and leisure activities. In this way, the nature of the British people loving sports has been fully mobilized. Fitness clubs with diverse activities and various organizational forms were established across the country. Accompanied by this phemomenon, the number of people involved in fitness and leisure activities increased continually, and sports consumption and credit were rising, which played an important role in the development of British sports industry.

British consciousness on sports consumption and their passion for sports laid a material foundation for the development of British sporting goods industry. Driven by the the rapid development of professional sports industry and sports fitness and leisure industry, many other industries of British society engaged in the sport industry in the past, which led to a sophisticated and rationalized structure of British sports industry and ensured British sports industry in a leading position in the world. 


\section{Conclusion}

After analyzing the evolution history of three developed countries, we can draw a conclusion that the high-speed development of international economy, the rapid development of sports services and comprehensive legal system, sound macro policy management system are the main factors that lead to the rapid development of these countries' sports industry. In October 2014, the State Council issued a document named 'Opinions on Accelerating the Development of Sports Industry to Promote Sports Consumption', which has injected new vitality for the reform and development of sports industry. Through analyzing the characteristics of development and history of sports industry stucture in developed countries in the world, there is no doubt that summarizing their historical experience could provide powerful reference to optimize and upgrade the effective implementation of the sports industry structure in China.

\section{References}

[1] Bai JR, Yi SH. The Relationship between Service Economy and the Comprehensive National Strength [J]. Journal of Finance and Economics, 2004 (8): 22

[2] Ling XP. The research of our country sports industry development present situation and countermeasure [J]. Journal of Sports Science, 2006 (2): 34.

[3] Zhao QB, Zhao W. The enlightenment from Characteristics and mode of development of sports industry in developed countries [J]. Journal of Beijing Sports University Press, 2004 (10): 55.

[4] Yang ZHH, XIANG XL, Chao FY. The research about the sustainable development of our country's sports industry [J]. Journal of Shanghai Institute of Physical Education, 2006 (3):35.

[5] Lu XC. The rearch about Japanese sports industry [M.]. Policies and Regulations Department of General Administration of Sport, 2003.

[6] Zhang L, Li M. The characteristic of the foreign professional sports clubs operating mechanism [J]. Journal of Shanghai Institute of Physical Education, 2001 (01): 34.

[7] Liu JN. The general picture of American sports industry development and its sociological factors' analysis [J]. Journal of Guangzhou Institute of Physical Education, 2001 (01): 35.

[8] Wang ZP, Yuan YJ. Chinese sports industry Policy development history and characteristics [J].Journal of Shanghai Institute of Physical Education, 2008 (2): 55.

[9] Zhao QB. The main mode of economic development of sports industry in developed countries [J]. Journal of Beijing Sports University, 2004 (10): 89.

[10] General Administration of Sport. China's sports since Reform and opening's 30 years [M]. Beijing: people's sport press, 2008:34. 